\title{
Effect of Superplasticizer Dosage on Workability and Strength Characteristics of Concrete
}

\author{
Muhsen Salem ${ }^{1}$, Salahaldein Alsadey ${ }^{2}$ Megat Johari3 \\ ${ }^{1}$ (Department of Civil Engineering, College of Engineering/Zawia University, Libya) \\ ${ }^{2}$ (Department of Civil Engineering, College of Engineering/ Bani Waleed University, Libya) \\ ${ }^{3}$ (Department of Civil Engineering, College of Engineering/Universiti Sains Malaysia, Malaysia)
}

\begin{abstract}
The use of chemical admixtures in concrete is a common solution to achieve full compaction particularly where reinforcement congestion and shortage of skilled workers. The past researchers have been underscored the use of chemical admixtures imparts the desirable properties to concrete in both fresh and hardened state. This paper has been made an attempt to study the influence of superplasticizer dose of $400 \mathrm{ml}$, $600 \mathrm{ml}, 800 \mathrm{ml}, 1000 \mathrm{ml}$ and $1200 \mathrm{ml} / 100 \mathrm{~kg}$ of cement on performance of Concrete. The experimental tests for fresh and hardened properties of concrete for three mixes of $30 \mathrm{MPa}$ grade are studied and the results are compared with normal concrete. The tests considered for study are, slump test, slump loss, flow table and compressive strength test The results show that for the constant water cement ratio, increase of superplasticizer dose in properties of concrete leads to gain of good workability. Moreover, there is also increase in compressive strength than that of normal concrete mix.
\end{abstract}

Keywords: Compressive strength, Normal concrete, Super plasticizer, Workability.

\section{Introduction}

Concrete structure is the most common type of structure, and it keeps developing and improving day after day to meet up with the global requirements, this structure is basically a mixture of cement, water, sand, and coarse aggregate. However, cement considered as the most expensive and significant ingredient in concrete production. Concrete is the major structural material widely consumed in the world, after water. Most of the infrastructure and building construction in the world are using concrete as construction material. High strength concrete has been commonly used because most of the rheological, mechanical and durability properties of these materials are better than those of conventional concretes. Generally, there are four main categories of superplasticizer: sulfonated melamine- formaldehyde condensates, sulfonated naphthalene- formaldehyde condensaes, modified lignosulfonates and others such as sulfonic- acid esters and carbohydrate esters. Effects of superplasticizer are obvious, i.e. to produce concrete with a very high workability or concrete with a very high strength. Mechanism of superplasticizer is through giving the cement particles highly negative charge so that they repel each other due to the same electrostatic charge. By deflocculating the cement particles, more water is provided for concrete mixing [1].

For general usage, dosage of superplasticizer is between $1-31 / \mathrm{m}^{3}$. However, the dosage can be increased to as high as $5-20 \mathrm{l} / \mathrm{m}^{3}$. Since concentration of superplasticizer is different, any comparison of performance should be made on the basis of the amount of solids, and not on the total mass. Effectiveness of a given dosage of superplasticizer depends on the water/cement ratio. Effectiveness increases when w/c decreases. Compatibility with actual cement is one of the most important parameters that needed to be considered, and it is not recommended that the cement and superplasticizer conform the standard separately [1]. There are few advantages obtained when superplasticizer is used: produce high workability concrete with constant cement content and strength, with objective for easy placing and compaction; produce concrete with normal workability, but lower water requirement; production of concrete with combination of high workability and low water content; and designing a normal strength and workability concrete with less cement content [2].

The superplasticizers have positive effects on properties of concrete, both in the fresh and hardened states. In the fresh state, superplasticizer normally reduce tendency to bleeding due to the reduction in water/ cement ratio or water content of concrete. However, if water/ cement ratio is maintained, there is tendency that superplasticizer prolong the time of set of concrete as more water is available to lubricate the mix [3].

In the case of hardened concrete, the use of superplasticizer increase compressive strength by enhancing the effectiveness of compaction to produce denser concrete. Risk of drying shrinkage will be reduced by retaining the concrete in liquid state for longer period of time. In addition, rate of carbonation become slower when water/ cement ratio is decreased with the presence of superplasticizer [4]. The influence of a superplasticizer on workability of concrete confirmed that slump of fresh concrete can be optionally controlled in all mix- designs if Superplasticizer is added. Since workability of low water/cement ratio concrete is difficult to control, addition of Superplasticizer can usefully maintain the initial slump of mixed concrete. In addition, 
they claimed that superplasticizer can really produce a good quality concrete by increasing the density of concrete, through significant reduction in water requirement and slump loss [6]. The reason for widespread usage of admixtures is that admixtures are able to impart considerable physical and economic benefits with respect to concrete. However, usage of admixture is not remedy for poor quality of concrete due to the use of incorrect mix proportion, poor workmanship in concrete mixing and the problems caused by low quality raw materials selection $(5,6)$.

\section{Materials Used}

The materials used for study are cement, superplasticizer, fine and coarse aggregates. This type of concrete involves many factors that affect the deformability and segregation such as water- cement ratio and numerous properties of aggregates that is, volume, size distribution, void content, fine to coarse aggregate ratio, surface properties and density. Further, few tests of our interest are conducted as per codal provisions on concrete materials to determine their properties and suitability for the tests under consideration.

\subsection{Ordinary Portland cement}

The cement used in this study is a product from Cement Industries of Malaysia Berhad (CIMA), with a brand name blue lion. This type-I cement complies strictly with BS 12: 1991 where it is widely used in general construction, for example buildings, bridges and other precast concrete products. It is available in $50 \mathrm{~kg}$ bag.

\subsection{Mixing water}

Water is important to ensure continuous hydration process. Along the experiment, tap water is used for mixing and curing of concrete. The water must be free from reactive elements such as reactive ions and impurities to guarantee the quality of the concrete.

\subsection{Fine and Coarse aggregates}

Aggregate is important because it occupies about three- quarters of the volume of concrete. Usually, there are two types of aggregate used in concrete, which are fine and coarse aggregates. Many parameters needed to be considered in selection of aggregate, for instance, types of aggregate, size and shape of the particle, and the strength of the aggregate. All aggregate must be free from dust as the dust may affect the bonding between the aggregate and cement particles. The fine aggregate used in this investigation is river sand. The size range from $150 \mu \mathrm{m}, 300 \mu \mathrm{m}, 600 \mu \mathrm{m}, 1.18 \mathrm{~mm}, 2.36 \mathrm{~mm}$ and $5 \mathrm{~mm}$, with the specific gravity and water absorption of 2.46 and 1.5 respectively. Sieve analysis shows that the percentage passing $600 \mu \mathrm{m}$ is $26.76 \%$. Coarse aggregate used in this study is granite with a maximum size of $20 \mathrm{~mm}$. Water absorption and specific gravity of the aggregate are $0.614 \%$ and 2.66 respectively. In addition, aggregates should be cleaned before mixing to wash away the fine particles that stick on the surface of the aggregate.

\subsection{Superplasticizer}

The superplasticizer used in this study is Glenium C380. It is a new superplasticizer, which not only suitable for prestressed concrete, but also for other types of concrete. One of its benefits is that it can improve both early and final strength. In addition, slump retention and workability of concrete also enhanced by using Glenium C 380 if compared with traditional superplasticizer. The table 1 is the descriptions on properties of the superplasticizer as supplied by the manufacturer.

Table 1 Properties of Superplasticiser Used

\begin{tabular}{|c|c|}
\hline Physical state & Liquid \\
\hline Colour & Brown \\
\hline Odour & Specific odour \\
\hline Freezing temperature & $-3.0^{\circ} \mathrm{C}$ \\
\hline Boiling point & $>100^{\circ} \mathrm{C}$ \\
\hline Melting point & n.d. \\
\hline Flash point & n.a. (aqueous) \\
\hline P1 & n.a \\
\hline EPL(in) & n.a \\
\hline Vapour pressure & n.a \\
\hline Vapour density & Approx. 1.08 gcm- ${ }^{3} @ 20^{\circ} \mathrm{C}$ \\
\hline Relative density & Soluble \\
\hline Solubility & Approx. 7.0 \\
\hline pH value & n.a. \\
\hline Viscosity & \\
\hline & Aple \\
\hline
\end{tabular}




\section{Concrete Mix Proportion}

In order to study the effect of superplasticizer on the properties of fresh and hardened concrete, seven mixes are prepared. After design calculation, the concrete of Grade 30 with water/cement required to obtain slump between ranges $60-180 \mathrm{~mm}$ is 0.6 . However, as the aggregate used in the experiment is in dry condition, the weight of mixing water had to be increased by the amount required for absorption by the aggregates. Hence, water/ cement ratio becomes 0.66 [7]. On the hand, when superplasticizer is added to the mixes, the slump becomes higher than $180 \mathrm{~mm}$. As a result, $15 \%$ of water (Neville, 2005) is reduced until the water/ cement ratio is only 0.56 . Therefore, two controls are used in this experiment for comparison purposes. Details of the mixes are given in table 2 .

Table 2 Mix Design Details

\begin{tabular}{|c|c|c|c|c|c|c|c|c|}
\hline \multirow[t]{3}{*}{ Sample } & \multirow{3}{*}{$\begin{array}{l}\text { Dimension }(\mathrm{mm}) \\
\mathrm{L} \times \mathrm{B} \times \mathrm{H}\end{array}$} & \multicolumn{7}{|c|}{ Concrete Mix with $\mathrm{SP}\left(\mathrm{Kg} / \mathrm{m}^{3}\right)$ to the Grade 30} \\
\hline & & Cement & Fine aggregate & Coarse aggregate & Water & SP & \multirow[b]{2}{*}{$\mathrm{W} / \mathrm{C}$} & slump \\
\hline & & $\mathrm{kg} / \mathrm{m}^{3}$ & $\mathrm{~kg} / \mathrm{m}^{3}$ & $\mathrm{~kg} / \mathrm{m}^{3}$ & $\mathrm{~kg} / \mathrm{m}^{3}$ & $\mathrm{ml} / \mathrm{m}^{3}$ & & $\mathrm{~mm}$ \\
\hline Control Mix M & $150 \times 150 \times 150$ & 340 & 965 & 865 & 190 & - & 0.56 & 45 \\
\hline Control Mix M1 & $150 \times 150 \times 150$ & 340 & 965 & 865 & 225 & - & 0.66 & 125 \\
\hline MS1 400ml/100kg & $150 \times 150 \times 150$ & 340 & 965 & 865 & 190 & 1360 & 0.56 & 140 \\
\hline MS2 $600 \mathrm{ml} / 100 \mathrm{~kg}$ & $150 \times 150 \times 150$ & 340 & 965 & 865 & 190 & 2040 & 0.56 & 155 \\
\hline MS3 $800 \mathrm{ml} / 100 \mathrm{~kg}$ & $150 \times 150 \times 150$ & 340 & 965 & 865 & 190 & 2720 & 0.56 & 165 \\
\hline MS4 1000ml/100kg & $150 \times 150 \times 150$ & 340 & 965 & 865 & 190 & 3400 & 0.56 & 180 \\
\hline MS5 $1200 \mathrm{ml} / 100 \mathrm{~kg}$ & $150 \times 150 \times 150$ & 340 & 965 & 865 & 190 & 4080 & 0.56 & 190 \\
\hline
\end{tabular}

\section{Experimental Program}

The proposed study has undertaken the various tests on mix are, slump, slump loss, flow table and compressive strength at 1 th, 3 th, 7 th and 28 th days. The complete mixing operation is performed using drinkable water and table vibrator is used while casting mix. After casting the mix in cube mould for 24 hours then the same is cured in normal water of curing tank having room temperature.

\section{Results And Discussion}

Tests needed to be carried out in order to investigate the properties of the concrete. Basically, there are three types of testing, namely control testing, compliance testing and secondary testing. Control testing is used to ensure acceptable supplied materials are available, whereas, compliance testing is to judge compliance of the material with the given specifications. Lastly, secondary testing is used when there is doubt about the reliability of control and compliance results [8]. Usually, the objective of fresh concrete testing is to determine the workability of the sample, since workability is important to ensure sufficient compaction on the concrete to avoid excessive porosity that might affect the quality of the concrete. On the other hand, tests on harden concrete is to observe its strength and other properties of concrete so that the effect of both retarder and superplasticizer could be quantified [9].

\subsection{Effect of Superplasticizer on Slump Loss}

Table 3 shows the slump values for all the batches of concrete tested for workability. The workability of concrete enhanced with addition of superplasticizer with constant W/C ratio. However, the workability of concrete is one of the most important criteria that should be always be kept in check for long duration depending up on the retention time which is calculated keeping the distance between the site and the ready mixed concrete plant. The data are recorded and being shown to observe the relation between dosages of superplasticizer and slump loss. The values of slump loss for different dosages of superplasticizer are then plotted as a graph as shown in Fig 1.

Table 3 Slump Loss for Superplasticizer Concrete

\begin{tabular}{|c|c|c|c|c|c|c|c|c|}
\hline \multirow[t]{2}{*}{ Concrete mix } & \multicolumn{8}{|c|}{ Slump (mm) } \\
\hline & $0 \mathrm{~min}$ & $30 \mathrm{~min}$ & $60 \mathrm{~min}$ & $90 \mathrm{~min}$ & $120 \mathrm{~min}$ & $180 \mathrm{~min}$ & $240 \mathrm{~min}$ & $300 \mathrm{~min}$ \\
\hline Control M & 40 & 35 & 20 & 10 & 0 & 0 & 0 & 0 \\
\hline Control M1 & 130 & 100 & 70 & 50 & 30 & 15 & 10 & 0 \\
\hline $400 \mathrm{ml} / 100 \mathrm{~kg}$ of cement(MS1) & 150 & 110 & 80 & 60 & 35 & 20 & 10 & 0 \\
\hline $600 \mathrm{ml} / 100 \mathrm{~kg}$ of cement(MS2) & 160 & 140 & 90 & 65 & 35 & 25 & 13 & 0 \\
\hline $800 \mathrm{ml} / 100 \mathrm{~kg}$ of cement(MS3) & 165 & 140 & 110 & 95 & 73 & 50 & 20 & 0 \\
\hline $1000 \mathrm{ml} / 100 \mathrm{~kg}$ of cement(MS4) & 170 & 150 & 140 & 115 & 65 & 47 & 15 & 0 \\
\hline $1200 \mathrm{ml} / 100 \mathrm{~kg}$ of cement(MS5) & 190 & 170 & 155 & 123 & 76 & 52 & 25 & 10 \\
\hline
\end{tabular}




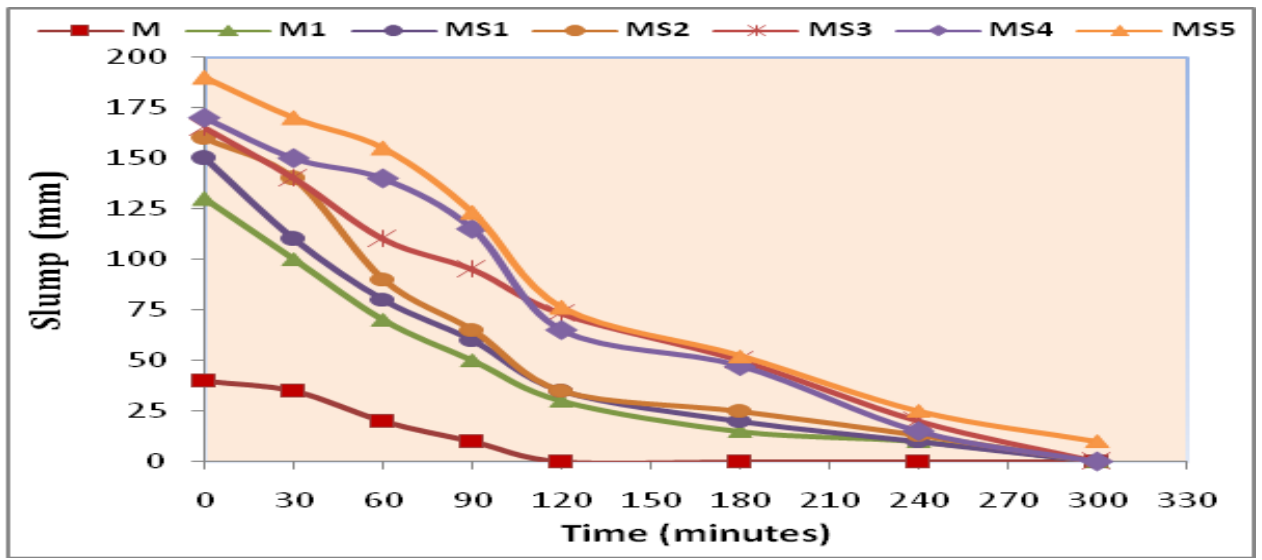

Figure 1 Effect of Superplasticizer Dosage on Slump Loss

The above Graphs show slump in mm against elapse of different dosages of superplasticizer. At Fig 1 it is clear that with the increase of superplasticizer the slump (mm) also increases. Another line graph is plotted here to understand the slump loss condition in total five specimens. M and M1 specimen is control specimen here that is why it does not fabricate with any superplasticizer. But MS1, MS2, MS3, MS4 and MS5 contains SP (Glenium C380) in a ratio 0.4, 0.6, 0.8, 1.0 and 1.2 consecutively using admixture dosage of 400, 600, 800, 1000 and $1200 \mathrm{ml} / 100 \mathrm{~kg}$ of cement. At maximum dosage the slump value in $\mathrm{mm}$ also maximum and it shows higher value at specimen MS5. When observation is done on the content of superplasticizer, increase in dosage of the chemical admixture will decelerate the rate of setting of concrete, the superplasticizer will help to retain the concrete in liquid state for a longer time, and hence, reduce the slump loss during the transportation of concrete to the site. However, over dosage of this admixture will lead to high slump loss, which will not give true slump that as what we expect and desire.

\subsection{Effect of Superplasticizer on Workability on Flow Table}

The results for flow table test of superplasticizer concrete are shown in table 4. The data are recorded and being shown in the manner of increasing dosage of superplasticizer. The values of flow table for different dosages of superplasticizer are then plotted as a graph as shown in Fig 2.

Table 4 Flow Table for Superplasticizer Concrete

\begin{tabular}{|l|l|l|l|l|l|l|l|l|}
\hline \multirow{2}{*}{ Concrete mix } & \multicolumn{6}{l|}{ Flow table $(\mathrm{mm})$} \\
\cline { 2 - 10 } & $0 \mathrm{~min}$ & $30 \mathrm{~min}$ & $60 \mathrm{~min}$ & $90 \mathrm{~min}$ & $120 \mathrm{~min}$ & $180 \mathrm{~min}$ & $240 \mathrm{~min}$ & $300 \mathrm{~min}$ \\
\hline Control M & 350 & 340 & 330 & 320 & 320 & 320 & 320 & 320 \\
\hline Control M1 & 450 & 440 & 395 & 375 & 350 & 330 & 330 & 330 \\
\hline $400 \mathrm{ml} / 100 \mathrm{~kg}$ of cement & 470 & 440 & 410 & 370 & 360 & 340 & 340 & 340 \\
\hline $600 \mathrm{ml} / 100 \mathrm{~kg}$ of cement & 510 & 450 & 400 & 380 & 360 & 350 & 350 & 350 \\
\hline $800 \mathrm{ml} / 100 \mathrm{~kg}$ of cement & 530 & 500 & 480 & 450 & 420 & 400 & 390 & 380 \\
\hline $1000 \mathrm{ml} / 100 \mathrm{~kg}$ of cement & 580 & 520 & 480 & 450 & 420 & 400 & 390 & 380 \\
\hline $1200 \mathrm{ml} / 100 \mathrm{~kg}$ of cement & 650 & 600 & 540 & 470 & 400 & 385 & 380 & 380 \\
\hline
\end{tabular}

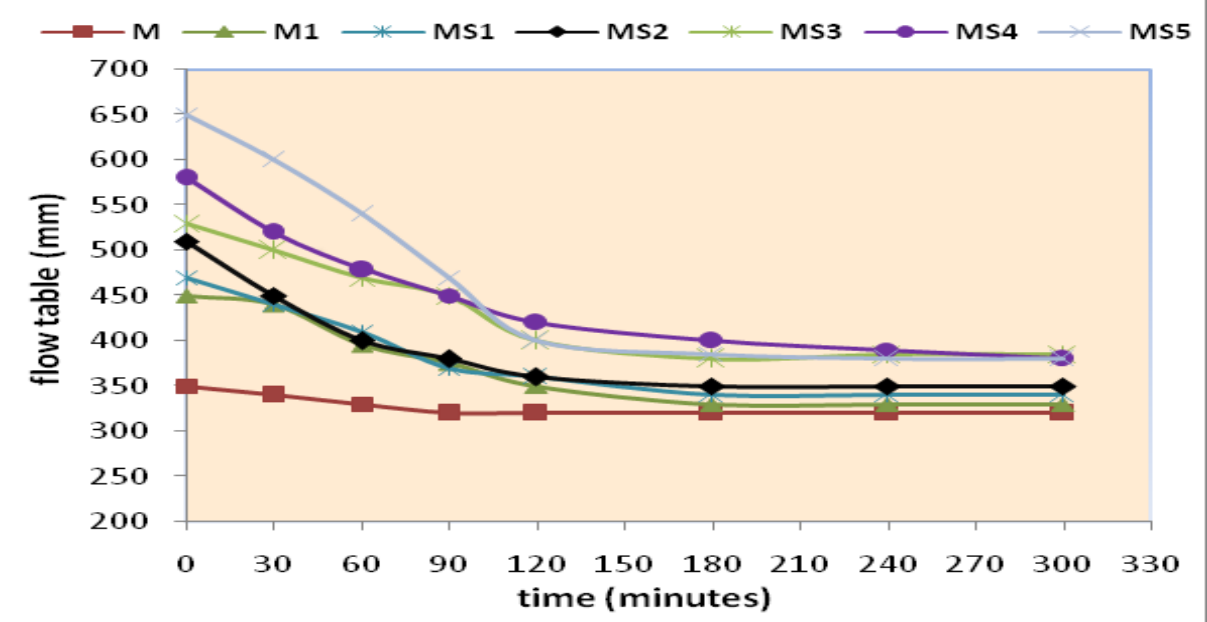

Figure 2 Effect of Superplasticizer Dosage on Flow Table 
Flow table is used to check the workability and cohesiveness of the concrete. From the graph obtained, diameter of spread of concrete reduces with time. It is acceptable and understandable since concrete will set as hydration process proceeds between the cement particles and water. Solidification of concrete will then reduce the workability and hence, present small diameter of spread of concrete. When superplasticizer is added to the concrete, the diameter of spread concrete increases due to higher amount of water is provided for lubricating the mix. Even though of chemical admixture increase the diameter of spread of concrete, however, their mechanisms are totally different. For superplasticizer, it significantly increases the workability of concrete for the first two hours due to deflocculation and adsorption of highly negative charges on cement particles, then, its effect fades out when the concrete start to set after 2 hours from casting.

Before adding the chemical admixture, the concrete is less cohesive since they present small diameter of spread concrete (less than $500 \mathrm{~mm}$ ). According to BS 1881, Part 105: 1984; the concrete can only be considered as uniform and cohesive when they possess the diameter in the range between $(500-650 \mathrm{~mm})$. After adding the superplasticizer, this desired diameter is achieved. Hence, we can conclude that superplasticized concrete is cohesive according to BS 1881. In term of dosage, an increase in dosage of the admixture will help to increase the workability of concrete. However, superplasticizer increases the diameter significantly for the early age.

\subsection{Effect of Superplasticizer on Compressive Strength}

Compressive strength of concrete with different dosage of superplasticizer is shown in table 5. This test is performed on 1, 3, 7 and 28 days. The values of compressive strength for the different dosage of superplasticizer are then shown as a graph in Fig 3.

Table 5 Compressive Strength of Superplasticizer Concrete

\begin{tabular}{|l|l|l|l|l|}
\hline \multirow{2}{*}{ Concrete mix } & \multicolumn{4}{|l|}{ Compressive strength in $/ \mathrm{mm}^{2}$} \\
\cline { 2 - 5 } & 1 day & 3 days & 7 days & 28 days \\
\hline Control (M) (plain concrete) & 15.97 & 27 & 36.31 & 42.22 \\
\hline Control (M1) (plain concrete & 12.75 & 23.23 & 29.99 & 35.29 \\
\hline $400 \mathrm{ml} / 100 \mathrm{~kg}$ of cement(MS1) & 16.77 & 31.16 & 36.57 & 42.77 \\
\hline $600 \mathrm{ml} / 100 \mathrm{~kg}$ of cement(MS2) & 20.05 & 34.18 & 42.92 & 44.61 \\
\hline $800 \mathrm{ml} / 100 \mathrm{~kg}$ of cement(MS3) & 20.41 & 34.38 & 41.17 & 46.79 \\
\hline $1000 \mathrm{ml} / 100 \mathrm{~kg}$ of cement(MS4) & 19.78 & 33.98 & 40.60 & 44.21 \\
\hline $1200 \mathrm{ml} / 100 \mathrm{~kg}$ of cement(MS5) & 20.00 & 32.84 & 40.70 & 42.46 \\
\hline
\end{tabular}

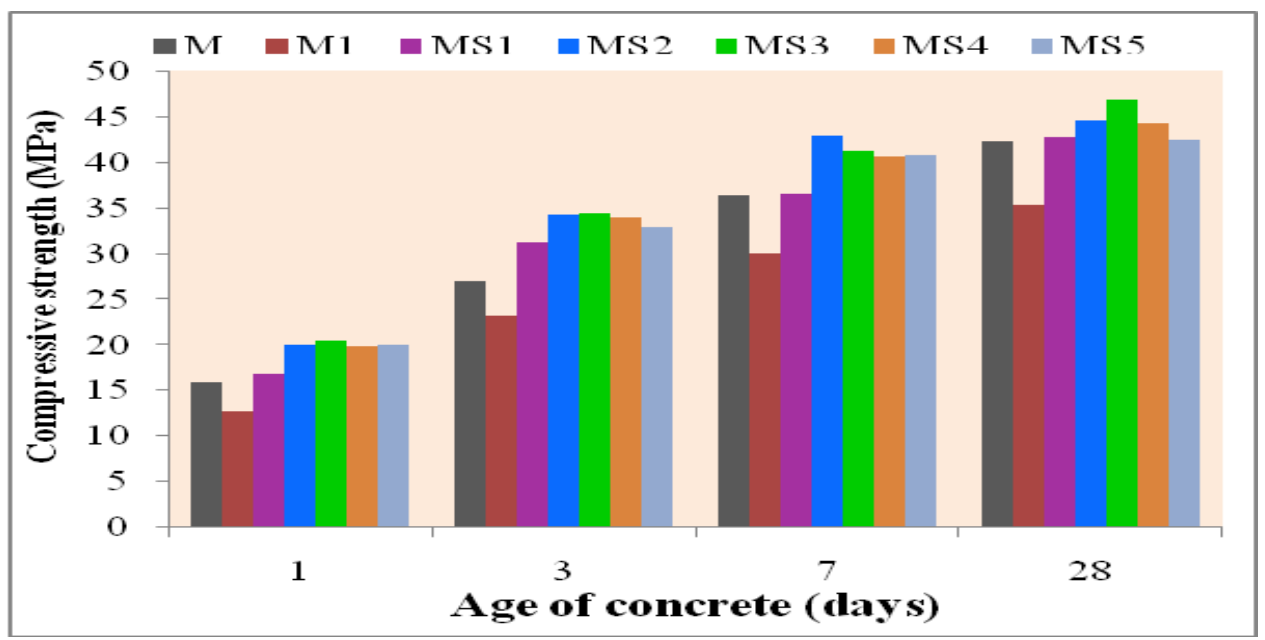

Figure 3 Compressive Strength of Concrete with Different Dosages of Superplasticizer

After conducting the experiment, a graph of compressive strength versus dosage of superplasticizer is shown at Fig 3. From the graph, it is clear that the strenth gains continuoulsy for addition of chemical admixtur and the compressive strength is increasing with the increment of superplasticizer dosage. It also visible from experiment that superplasticizer has a locontinuous strength gain for chemical admixture concrete is observed by the increase in compressive strength with age. At early age (1- 7 days from casting), the rate of strength gain is high since the reaction between the cement particles and water is active. When time goes by, the rate become lower, and hence, the slope of curve for age 7 to 28 days is less steep compared with its early age.

For superplasticizer, increase in dosage will increase the compressive strength for all ages. Since addition of superplasticizer will provide more water for concrete mixing, not only the hydration process will not be disturbed, but, it is accelerated by the additional water from deflocculation of cement particles. Hence, 
increase in dosage will increase the entrapped water and promote hydration of cement. Though increment in dosage of admixture will enhance the compressive strength, there is still an optimum limit for the usage of admixture. When the dosages go beyond this limit, increase in dosage will only reduce the compressive strength. This phenomenon occur since over dosage of superplasticizer will cause bleeding and segregation, which will affect the cohessiveness and uniformity of the concrete. As a result, compressive strength will reduce if the used dosage is beyond the optimum dosage.

\section{Conclusions}

The characteristic behaviour of concrete was studied using different dosages of superplasticizer on properties of concrete with strength of $30 \mathrm{MPa}$. The properties explored were workability (slump and flow table), workability retention and compressive strength. From the test results, following conclusions are:

1. From the results of the study, it is decided that by addition of superplasticizer the workability of concrete can be enhanced.

2. By using the proper chemical admixtures slump loss can be reduced to a great extent. In superplasticizer concrete effect is too high.

3. Inclusions of superplasticizer in concrete enable concrete to have a better cohesiveness without segregation, by increasing diameter of spread concrete to the range between $500-650 \mathrm{~mm}$. However, at very high dosages, cohesiveness reduces.

4. Compressive strength of concrete with addition of superplasticizer increases with all dosages of superplasticizer when cured in water for all ages.

\section{Acknowledgements}

This work has been supported by the School of Civil Engineering, Engineering Campus, Universiti Sains Malaysia, 14300 Nibong Tebal, Pulau Pinang.

\section{References}

[1] Neville A.M, 2005. Properties of concrete, Pearson. Prentice Hall, p 255- 262

[2] Ramachandran V. S., Beaudoin J. J.and Shihua., 1981. Concrete science. Heyden \& Son Ltd. p. 91,130- 138, 145.

[3] Salahaldein Alsadey (2012). Influence of Superplasticizer on Strength of Concrete. International Journal of Research in Engineering and Technology (IJRET) Vol. 1, No. 3, 2012 ISSN 2277 - 4378.

[4] Salahaldein Alsadey, (2012) Effects of Superplasticizing Admixture on Properties of Concrete Paper presented at International Conference on Transport, Environment and Civil Engineering (ICTECE' 2012). Kuala Lumpur (Malaysia), August 25-26, 2012.

[5] Salahaldein Alsadey , 2013 Effects of Superplasticizing and Retarding Admixtures on Properties of Concrete International Conference on Innovations in Engineering and Technology (ICIET), Bangkok (Thailand).

[6] Salahaldein Alsadey (2015). Effect of Superplasticizer on Fresh and Hardened Properties of Concrete. Journal of Agricultural Science and Engineering, American Institute of Science (AIS) Vol. 1, No. 2, 2015,pp. 70-74.

[7] Building Research Establishment Report, 1988. Design of normal concrete mixes.

[8] Bungey J. H. and Millard S. G.,1996. Testing of concrete in structures. Chapman \& Hall.

[9] Liew K. W, 2005. High strength concrete containing silica fume and metakaolin. University Sains Malaysia.

[10] BS1881-125: (method of mixing and sampling fresh concrete in the laboratory).

[11] British Standard Institution, BS 1881: Part 3 (1970). Methods of Making Curing and Test Specimens.

[12] British Standard Institution, BS 1881: Part 102 (1983). Methods for Determination of Slump.

[13] British Standard Institution, BS 1881: Part 116 (1983). Methods for Determination of Compressive Strength of Concrete Cube. 